\title{
Phylogenetic structure predicts capitular damage to Asteraceae better than origin or phylogenetic distance to natives
}

Post-print/Accepted manuscript

Steven B. Hill

Peter M. Kotanen

Hill, S.B. \& Kotanen, P.M. Oecologia (2011) 166: 843. doi:10.1007/s00442-011-1927-y

The final publication is available at Springer via http://dx.doi.org/10.1007/s00442-011-1927-y

\section{HOW TO CITE TSPACE ITEMS}

Always cite the published version, so the author(s) will receive recognition through services that track citation counts, e.g. Scopus. If you need to cite the page number of the TSpace version (original manuscript or accepted manuscript) because you cannot access the published version, then cite the TSpace version in addition to the published version using the permanent URI (handle) found on the record page. 
1 Phylogenetic structure predicts capitular damage to Asteraceae better than

\section{origin or phylogenetic distance to natives}

\author{
Steven B. Hill ${ }^{1}$ and Peter M. Kotanen ${ }^{2 *}$ \\ Department of Ecology and Evolutionary Biology \\ University of Toronto at Mississauga \\ 3359 Mississauga Road N \\ Mississauga ON \\ L5L 1C6 \\ Canada \\ tel: 905-828-5365; fax: 905-828-3792 \\ 1e-mail: sb.hill@utoronto.ca \\ 2e-mail: peter.kotanen@utoronto.ca \\ * Author for correspondence
}


16 Abstract Exotic species more closely related to native species may be more susceptible to attack

17 by native natural enemies, if host use is phylogenetically conserved. Where this is the case, the use

18 of phylogenies that include co-occurring native and exotic species may help to explain

19 interspecific variation in damage. In this study, we measured damage caused by pre-dispersal seed

20 predators to common native and exotic plants in the family Asteraceae. Damage was then mapped

21 onto a community phylogeny of this family. We tested the predictions that damage is

22 phylogenetically structured, that exotic plants experience lower damage than native species after

23 controlling for this structure, and that phylogenetically novel exotic species would experience

24 lower damage. Consistent with our first prediction, $63 \%$ of the variability in damage was

25 phylogenetically structured. When this structure was accounted for, exotic plants experienced

26 significantly lower damage than native plants, but species origin only accounted for 3\% of the

27 variability of capitular damage. Finally, there was no support for the phylogenetic novelty

28 prediction. These results suggest that interactions between exotic plants and their seed predators

29 may be strongly influenced by their phylogenetic position, but not by their relationship to locally

30 co-occurring native species. As well, the influence of a species' origin on the damage it

31 experiences often may be small relative to phylogenetically conserved traits.

32

33 Keywords Asteraceae, Darwin's Naturalization Hypothesis, Community phylogenetics, Enemy

34 Release Hypothesis, Invasion biology 


\section{Introduction}

The Enemy Release Hypothesis (ERH) predicts that non-indigenous (exotic) species leave many of their enemies behind in their native range, giving them an advantage over co-occurring native species in their invaded range (Keane and Crawley 2002; Torchin and Mitchell 2004; Mitchell et al. 2006). Tests of this hypothesis have found varied results: exotic species often experience reduced damage compared to natives (Torchin and Mitchell 2004; Liu and Stiling 2006), but exceptions are frequent (e.g., Agrawal et al. 2003; Parker and Hay 2005; Liu et al. 2007; Chun et al. 2010). This variation reflects the fact that exotic plants are likely to encounter new enemies in their invaded range (Hawkes 2007). Since host-use by enemies often is phylogenetically conserved (Odegaard et al. 2005; Brändle and Brandl 2006; Weiblen et al. 2006; Gilbert and Webb 2007; Pearse and Hipp 2009), such accumulation of enemies may be more likely for exotics that have close relatives in their introduced range (Strong et al. 1984; Lewinsohn et al. 2005; Dawson et al. 2009; Pearse and Hipp 2009; but see Zuefle et al. 2008).

The idea that the phylogenetic relationship between exotic and native species can influence invasion success is not new. Both de Candolle (1855) and Darwin (1859) reported that exotic plants in North America often belonged to novel genera, suggesting phylogenetically isolated species were better invaders; subsequently (Daehler 2001) this idea was named Darwin's Naturalization Hypothesis (DNH). Results of tests of this hypothesis vary; for instance, Daehler (2001) and Duncan and Williams (2002) found evidence against the idea, while other studies have found support (Strauss et al. 2006; Diez et al. 2008). Although other biotic interactions can potentially result in community-level patterns consistent with DNH, competition is usually assumed to be the mechanism (Darwin 1859; Webb et al. 2002). However, experimental evidence that compares competitive interactions among species based on their phylogenetic relatedness suggests that trends often tend to be weak; for instance, Cahill et al. (2008) found that there were 
only marginal relationships between competition and phylogenetic distance among a broad group of plants.

Alternatively, phylogenetically conserved interactions with natural enemies may cause patterns similar to those predicted by DNH through mechanisms such as apparent competition (Holt 1977; Mack 1996; Thuiller et al. 2010). Evidence that close relationship to native species affects the susceptibility of an invader to herbivory, however, is mixed (Cappuccino and Carpenter 2005; Dawson et al. 2009; Pearse and Hipp 2009; Hill and Kotanen 2009, 2010). For instance, we previously have shown that folivory on a diverse set of exotic plants in common gardens (but not natural populations) declined with increasing phylogenetic distance to native family members (Hill and Kotanen 2009). Despite this, we have found no relationship between phylogenetic isolation and folivory for natural populations of Asteraceae (Hill and Kotanen 2010).

Most studies evaluate enemy escape on plants using damage by folivorous insects (e.g. Agrawal and Kotanen 2003; Hill and Kotanen 2009, 2010). However, the phylogenetic component of enemy escape may be stronger for enemies that tend to have more specialized host-use (Frenzel and Brandl 2001; Joshi and Vrieling 2005); insects that consume seeds while still attached to the maternal plant (pre-dispersal seed predators) may offer a guild of such enemies. As well, damage by folivorous insects may only have weak effects on an invaders' fitness or vigor (Crawley 1989; Parker and Gilbert 2007), whereas pre-dispersal seed predators can cause dramatic declines in seed production (e.g. Hawthorn and Hayne 1978), reducing fitness and in some cases negatively affecting population growth (e.g., Louda and Potvin 1995; Louda et al. 1997, Louda and O'Brien 2002).

We have discussed foliar damage to exotic Asteraceae in a related study (Hill and Kotanen 2010). Here, we use an improved approach to describe damage to common members of this family 
83 by a different set of enemies: pre-dispersal seed predators. We tested the hypotheses that i)

84 patterns of seed loss are phylogenetically structured; ii) when accounting for this structure, pre-

85 dispersal damage to capitula is lower for exotic species than native species; and iii) that

phylogenetically novel exotic species experience lower rates of seed damage than those more

87

88

89

90

closely related to the native flora. Our results support the first hypothesis, and (weakly) the second, but we did not find that phylogenetically novel exotics experienced the least damage.

\section{Methods}

Study site and natural history

This study was conducted at the University of Toronto's Koffler Scientific Reserve (KSR) at Jokers Hill, Regional Municipality of York, in southern Ontario, Canada (44º2' N, 79³1' W, 300m ASL). This 350-ha site lies within the Oak Ridges Moraine, and is dominated by prominent hills with a thin organic layer over deep glacial sands. Vegetation is a mixture of old fields supporting a diverse range of native and exotic plants, hardwood (maple-beech-hemlock) forest, and conifer plantations. Further information on this site, including species lists, may be found at http://www.ksr.utoronto.ca.

An advantage of working at this site is that the local flora is well-known, allowing the construction of a complete community phylogeny (for species that were present between 1995 and 2008). We chose to work with plants in the Asteraceae because the phylogeny of this group is well understood (Funk et al. 2005), because this family includes many invasive species worldwide (Cadotte et al. 2009), and because it is well represented at KSR: 77 species ( 12\% of the local flora), of which 44 are native and 33 are exotic. We used species only if they were common enough to be reliably located; this potentially might bias against native and exotic species that were rare because of heavy damage, but provided good representation of the most prominent 
106 invasive and native taxa. Various examples of our study species are present in all major habitats

107 found on site, including old-field meadows, forest understories, wet meadows, and ponds.

108 Survey of capitular damage

From May to November 2008, we collected capitula for 35 representative species, including

11021 natives and 14 exotics (Fig. 1); these species were chosen based on their abundance in the field

111 and to represent as many habitats and lineages within the family as possible. Though all species

112 were sampled at the same field site, we incorporated individuals from up to 5 locations whenever

113 possible; for each species, sample locations were separated by at least $200 \mathrm{~m}$. Capitula were

114 collected from two to ten randomly sampled individuals per species at each of these locations. To

115 allow time for colonization by seed predators, we collected the capitula for each species two to

116 four weeks after first noting that flowering had begun. In the lab, capitula from each location were

117 mixed together, and between 50 to 100 were randomly selected to count; the resulting measure of

118 damage represented the average level of damage by pre-dispersal seed predators at the spatial scale

119 corresponding to the 350-ha Koffler Scientific Reserve. Capitula were counted as damaged if

120 larvae of any kind were found amongst the developing seeds or buried in the receptacle. We also

121 counted damage where larvae were absent, but insect larvae had clearly caused damage. This

122 included bore holes in seeds with missing endosperm, bore holes in the receptacle, and missing

123 seeds in the presence of insect frass. We detected numerous taxa of seed predators, including

124 Coleoptera, Diptera, and Hymenoptera, but did not attempt to distinguish between species or to

125 differentiate between native and exotic taxa. This approach is appropriate since it captures the sum

126 of pre-dispersal seed predation by all insects experienced by exotic plants: for enemy release to

127 apply, total damage must be reduced, not just the damage caused by co-evolved specialists (Maron

128 and Vilà 2001). 
For statistical analyses, damage for each species was calculated as the ratio of the number of

130 damaged capitula to total capitula summed across conspecific locations. This measure represents

131 the proportion of capitula attacked, rather than the proportion of seeds killed or the resulting

132 reduction in fitness. However, it was common for all developing seeds within a damaged

133 capitulum to be consumed, and in many cases damaged capitula were structurally disrupted (e.g.,

134 by gluing seed or pappus together), likely reducing the probability of normal dispersal of any

135 remaining seeds, and potentially resulting in the abortion of flower heads (e.g. Louda 1983).

136 Consequently, we feel our data provide an index of the intensity of seed loss, in addition to a

137 measurement of the frequency of capitular damage; in fact, severe damage often made it

138 impossible to determine how many seeds had been consumed, suggesting capitular damage often

139 may be a more reliable measure of insect attack than estimates based on counts of surviving seeds.

140 Data were transformed by calculating the associated Z-score for the proportion of damaged

141 capitula; when there were no capitula damaged, 0.001 was added to the zero-score to avoid

142 undefined numbers (Crawley 2007). Z-score transformations are similar to probit transformations,

143 and linearize the response variable, which typically is more appropriate for linear models (Crawley

144 2007).

145 Previous work has indicated that rates of attack may be influenced by capitulum size in

146 Asteraceae (Fenner et al. 2002). Therefore, prior to evaluating the relationship between the amount

147 of damage and phylogeny among our study species, we evaluated the relationship between damage

148 and capitulum size. For each species, we randomly selected 10 capitula to be measured. Each of

149 these was dissected longitudinally, and the diameter measured using calipers. For all species, the

150 Z-transformed proportion of damaged capitula was then regressed against average capitulum

151 diameter. 
152

153

154

155

156

157

158

159

160

161

162

163

164

165

166

167

168

169

170

171

172

173

174

175

Community phylogeny

The backbone of the Asteraceae community phylogeny was drawn from Funk et al. (2005).

Where polytomies existed, we supplemented the topology based on the following studies:

Erigeron (Noyes 2000), Hieracium (Gaskin and Wilson 2007), Lactuceae (Whitton et al. 1995),

Solidago (Semple and Cook 2006). Node ages for the resulting tree were then estimated using the

function "bladj" in PHYLOCOM v.4.0.1 (Webb and Donoghue 2005), with node age calibration points from a phylogeny based on $r b c L$ and $n d h F$ sequence data (Kim et al. 2005) (see Fig. 1).

Origin was distributed unevenly over phylogeny in our dataset, reflecting our choice of species: some lineages were dominated by natives, and others by exotics.

\section{Statistical Analyses}

To evaluate the phylogenetic component of herbivory, we used an eigenvector decomposition method (Diniz-Filho and de Sant'Ana 1998, Desdevises et al. 2003). Using a principal co-ordinate analysis ( $\mathrm{PCoA})$ of the phylogenetic distance matrix from the Asteraceae community phylogeny, 34 eigenvectors were extracted to predict phylogenetically structured damage ( $\mathrm{N}$ - 1 based on 35 species). These PCoA eigenvectors represent unique (orthogonal) potential predictors of phylogenetic structure in a trait (in this case capitular damage) based on distances between species at different phylogenetic scales. The approach is similar to spectral analysis in that the eigenvectors represent a series of sine waves with decreasing period (e.g.

Borcard and Legendre 2002); the first eigenvector has the broadest period (large-scale phylogenetic structure), and the last eigenvector has the smallest period (fine-scale phylogenetic structure). Eigenvectors that were related to capitular damage $(\mathrm{p} \leq 0.10)$ were selected based on a forward selection multiple regression. A p-value of 0.1 is typically used for a step-wise multiple regression; this allows for a less conservative model, reducing the risk that potentially informative predictors are removed. 
We then evaluated the independent contributions of origin (native versus exotic) and

177 phylogeny (significant eigenvectors) to patterns in capitular damage using the function varpart

178 from the vegetation analysis package vegan (Oksanen et al. 2009); this uses multiple regression

179 to calculate variance components $\left(\mathrm{r}^{2}\right.$ adj) associated with origin and phylogeny. This approach is the

180 same as one used for detecting phylogenetically structured environmental variation in a trait

181 (Desdevises et al. 2003). An analysis of covariance model was then used to test the hypothesis that

182 exotic species experience lower damage than native species while accounting for phylogenetically

183 structured variation. Origin was treated as a fixed factor, and each significant $(\mathrm{p} \leq 0.10)$

184 eigenvector was treated as a predictor. Analysis of the residuals from the linear model met the

185 assumptions of normality and homoscedasticity. We also used a one-tailed t-test of

186 phylogenetically independent contrasts (PICs) to test the hypothesis that exotic species

187 experienced lower damage than native species (Felsenstein 1985); PICs were calculated using the

188 function "aot" in the statistical package PHYLOCOM (Webb et al. 2008); t-tests were calculated

189 using Excel.

190

To determine if phylogenetically novel invaders experienced lower capitular damage than

191 those more closely related to native Asteraceae at KSR, four predictors of phylogenetic novelty

192 were calculated: i) mean distance to all native and exotic Asteraceae, ii) mean distance to closest

193 native or exotic relative, iii) mean distance to all native taxa, and iv) mean distance to closest

194 native taxa. Distances among individual taxa (in years of divergence) were based on the tip-to-tip

195 measurements given the branch lengths in the Asteraceae community phylogeny. Z-transformed

196 capitular damage was then regressed against each of these predictors.

197 All analyses were completed using R (R Development Core Team 2006) or JMP v5.0 (SAS

198 2002). 


\section{Results}

200 Capitulum size and damage

201 We were unable to detect an effect of capitulum size on rates of attack using regression $\left(\mathrm{t}_{33}=\right.$ 202 0.753, $\mathrm{p}=0.457$ ). We therefore did not include this as a predictor in any further analyses.

\section{Origin versus Phylogeny}

204 The majority of variation in capitular damage was explained by phylogeny $\left(\mathrm{r}^{2}{ }_{\text {adj }}=0.63\right)$.

205 Regressions between damage and eigenvector score often indicated clumping of data and/or 206 isolated datapoints, in part as a consequence of the statistical approach used. Nonetheless, five 207 eigenvectors were significantly related to damage (Fig. 2; Table 1) and were associated with 208 phylogenetic structures at various scales (Fig. 1): eigenvectors two and three were associated with 209 relatively broad phylogenetic patterns in damage, eigenvector eight was associated with 210 intermediate phylogenetic patterns, and eigenvectors 19 and 20 were associated with fine-scale 211 patterns in damage. The broader-scale eigenvectors detected higher rates of damage among species

212 in lineage 2a compared to species in lineages 2b, and generally higher rates of damage in lineage

213 3a compared to 3b (Fig. 1). The intermediate-scale eigenvector detected higher rates of damage for

214 Achillea millefolium and Chrysanthemum leucanthemum, versus other species in the same 215 respective clades. The fine-scale eigenvectors detected higher damage for Rudbeckia hirta, 216 compared to other species belonging to the same lineage, and higher damage for Antennaria 217 neglecta, compared to other species in its lineage.

218 Native versus Exotic

219 Capitular damage was similar for native and exotic species when no phylogenetic correction 220 was made (one-tailed t-test: $t_{33}=-0.709, \mathrm{p}=0.242$ ). When phylogenetic structure in damage was 221 accounted for, however, damage to exotic species was less than damage to native species (one222 tailed test: $\left.\mathrm{t}_{28}=1.865, \mathrm{p}=0.036\right)$ (Table 1$)$. Despite the loss of degrees of freedom resulting from 
223 the clustering of native versus exotic species in our phylogeny, this result was further supported

224 using phylogenetically independent contrasts of the difference between damage on native versus

225 exotic plants (mean difference \pm SE: $0.16 \pm 0.052, \mathrm{t}_{4}=3.073, \mathrm{p}=0.019$ ). Nonetheless, species'

226 origins accounted for a very low percent of explained variation in capitular damage $\left(r^{2}{ }_{\text {adj }}=0.03\right)$.

227 The variance partitioning approach also evaluated the combined influence of phylogeny and

228 origin; however, essentially none of the variability in capitular damage was explained by this

229 combination $\left(\mathrm{r}^{2}{ }_{\text {adj }}<0.01\right)$.

230 Phylogenetic novelty

231 The prediction of decreased capitular damage for phylogenetically novel exotic species was

232 not supported. Damage was not statistically related to any of the four phylogenetic distance

233 measures for exotic species: distance to all Asteraceae $\left(\mathrm{F}_{1,12}=2.386, \mathrm{p}=0.148\right)$, b) distance to

234 closest Asteraceae $\left(F_{1,12}=0.011, p=0.916\right)$, mean distance to all native Asteraceae $\left(F_{1,12}=1.290\right.$,

$235 \mathrm{p}=0.278)$, and mean distance to closest native Asteraceae $\left(\mathrm{F}_{1,12}=1.177, \mathrm{p}=0.299\right)$ (Fig. 3). We

236 suspected that high rates of capitular damage on Cirsium arvense and Arctium minus were in part

237 the result of introduced insects, possibly including biocontrol species (Zwölfer 1998; Mason and

238 Huber 2002). For Arctium, much of the damage likely was inflicted by the burdock moth,

239 Metzneria lappella Zeller (Gelechiidae), which was introduced to Canada in the 19th century and

240 is now abundant (Gross et al. 1980); for Cirsium, the introduced weevil Rhinocyllus conicus

241 Froeh. was common, and a variety of other native and introduced insects are possible (Moore

242 1975; Zwölfer 1998; Louda and O'Brien 2002; Louda et al. 2003). However, even when data for

243 these two species were removed from the phylogenetic distance regressions, none had significant

244 slopes $(0.554 \leq \mathrm{p} \leq 0.907$ for all cases $)$. 
Discussion

Whether exotic species are likely to accumulate enemies may influence their success and

247 invasiveness in new environments (Maron and Vilà 2001; Levine et al. 2004; Hawkes 2007). In

248 this study we predicted that capitular damage on locally co-occurring native and exotic Asteraceae

249 would be phylogenetically structured, that after accounting for this structure, exotic species would

250 experience lower damage than natives, and that exotics least closely related to native species

251 would experience the lowest rates of damage. We show strong evidence that damage to common

252 native and exotic Asteraceae is phylogenetically structured. After correcting for this phylogenetic

253 structure in damage, we found that exotic species experienced significantly lower damage, though

254 the fraction of variance explained was small. Our data, however, were not consistent with the 255 prediction that phylogenetic novelty results in lower susceptibility to enemies: exotic species

256 consistently experienced rates of damage that were independent of their evolutionary distance

257 from locally co-occurring native and exotic confamilials.

258 The strong relationship between damage and phylogeny is convincing evidence that

259 evolutionary history has a large impact on susceptibility to pre-dispersal seed predators of native

260 and exotic plants within the Asteraceae. The eigenvector approach that was used also revealed that

261 phylogenetically structured damage exists at multiple scales. Broad-scale patterns, for example, 262 existed between plants in the tribes Cardueae and Lactuceae (lineages 2a and 2b, Fig. 1); at finer

263 phylogenetic scales, Rudbeckia hirta and Antennaria neglecta both experienced higher rates of

264 damage than other species in their respective lineages. The strength of phylogeny as a predictor of

265 capitular damage suggests that evolutionary history may be a better predictor of damage by pre-

266 dispersal seed predators than a host's place of origin.

267 The combined effect of origin and phylogeny (Desdevises et al. 2003) did not explain any

268 additional variation in capitular damage. Although some lineages in our dataset were dominated by 
exotics and others by natives, this result suggests that any association between exotic status and particular lineages didn't consistently bias our results. However, since native and exotic species in

271 our study set tended to be over-represented within different broad lineages, there were few fine272 scale comparisons to be made.

273 We considered only relatively common exotics, which might be expected to have benefitted 274 most from enemy release; nonetheless, even for these species, any reduction in damage relative to 275 natives apparently was small. The lack of an effect of origin for non-corrected damage indicates 276 that the exotic Asteraceae in this study have been colonized by pre-dispersal seed predators 277 (including introduced insects) since their introduction to North America. This contrasts with the 278 results of Fenner and Lee (2001), who found in a phylogenetically non-corrected analysis that 279 exotic Asteraceae in New Zealand had greatly reduced rates of pre-dispersal seed predators 280 compared to native populations. This discrepancy likely reflects the phylogenetic and geographical 281 isolation of the New Zealand flora (Fenner and Lee 2001); in contrast, a European exotic plant in 282 North America may be much more likely to encounter relatives, and the enemies of those relatives. 283 In fact, in our study, capitular damage was higher in some exotics than in most native species. For 284 instance, Arctium minus had the highest proportion (89\%) of damaged capitula, even though it is 285 an exotic, while native species such as Bidens cernua, Eupatorium perfoliatum, and Gnaphalium 286 obtusifolium had no evidence of damaged capitula.

287 In contrast, we found exotics experienced lower rates of pre-dispersal seed predation than 288 related native species when phylogenetic structure was accounted for. This indicates that exotics 289 experience less damage than would be expected relative to related species; however, this was such 290 a weak effect that it was masked by phylogenetic variability in the uncorrected dataset. This 291 suggests that detecting reductions in enemy use, and therefore enemy release of exotic species, 
may be difficult without detailed knowledge of the local flora and the evolutionary history of a community to which an exotic is introduced.

The apparent lack of relationship between damage and phylogenetic distance of invaders to co-occurring family members suggests that the degree of evolutionary divergence among these plants had a minimal effect on their susceptibility to attack. This contrasts with studies which have found damage to exotics decreases with phylogenetic distance from natives in common gardens (Dawson et al. 2009; Hill and Kotanen 2009; Pearse and Hipp 2009), though this effect is often weak (e.g., Hill and Kotanen 2009). However, our results do resemble those from our study of folivory in Asteraceae (Hill and Kotanen 2010), which also failed to detect a decline in damage with phylogenetic distance in natural populations. These results suggest that any effects of phylogenetic distance among these relatively closely-related (confamilial) species are too weak to be detected against a background of natural variation. Instead, the large component of variability in damage that was explained by the phylogenetic eigenvectors $\left(r^{2}\right.$ adj $\left.=0.63\right)$ is convincing evidence that processes that result in similar levels of capitular damage are conserved among sublineages within the family, regardless of their origin.

Implications for ERH and DNH

The idea that exotic species experience less damage than natives (Keane and Crawley 2002) is weakly supported here. However, this reduced enemy susceptibility was detected only when phylogenetic relatedness was controlled. This suggests that enemy release may best be considered a relative process: an exotic may experience less damage than expected based on its evolutionary relationship to co-occurring natives, rather than simply a reduction compared to the average native. Future tests of the ERH may benefit from including an explicit phylogenetic component; this may help to explain the varied results among case studies in the literature (Maron and Vilà 2001; Colautti et al. 2004; Liu and Stiling 2006; Chun et al. 2010). 
The prediction that pre-dispersal seed predation would be negatively related to phylogenetic novelty was rejected for all four phylogenetic distance measures. This resembles the lack of effect

318 we detected for folivory (Hill and Kotanen 2010), even though it might be expected that greater

319 host-specificity by seed predators might have led to a stronger result. This implies that pre-

320 dispersal seed predators are unlikely to produce the patterns of co-occurrence predicted by

321 Darwin's Naturalization Hypothesis. Since the proportion of capitula damaged nonetheless had a 322 strong phylogenetic signal, phylogenetically-conserved characters may be much more important

323 for determining rates of seed predation than origin. One likely candidate is capitulum size: larger

324 capitula tend to be at a greater risk of seed parasitism (Fenner et al. 2002). Nonetheless, our data

325 did not support this pattern. Identifying the characters responsible for phylogenetic signals in rates

326 of attack by enemies and how well they are conserved should help in prediction of susceptibility to

327 enemies, and in understanding where DNH may or may not operate.

328 Acknowledgements This research was supported by NSERC Discovery and Equipment Grants

329 (PMK), an NSERC PGS-D (SBH), and the Koffler Scientific Reserve at Jokers Hill. Thanks to

330 Kateryna Kostyukova for her help, Andrew MacDonald and Megan Saunders for their support,

331 discussions, and field assistance, and two anonymous reviewers for their comments. All of the

332 experiments conducted in this study comply with the current laws of Canada. This is a publication

333 of the Koffler Scientific Reserve. 
335

336

337

338

339

340

341

342

343

344

345

346

347

348

349

350

351

352

353

354

355

356

357

\section{References}

Agrawal AA, Kotanen PM (2003) Herbivores and the success of exotic plants: a phylogenetically controlled experiment. Ecol Lett 6:712-715

Borcard D, Legendre P (2002) All-scale spatial analysis of ecological data by means of principal coordinates of neighbour matrices. Ecol Model 153:51-68

Brändle M, Brandl R (2006) Is the composition of phytophagous insects and parasitic fungi among trees predictable? Oikos 113:296-304

Cadotte MW, Hamilton MA, Murray, BR (2009) Phylogenetic relatedness and plant invader success across two spatial scales. Divers Distrib 15:481-488

Cahill JF, Kembel SW, Lamb EG, Keddy PA (2008) Does phylogenetic relatedness influence the strength of competition among vascular plants? Perspect Plant Ecol 10:41-50

de Candolle ALP (1855) Géographie botanique raissoné. V. Masson, Paris.

Cappuccino N, Carpenter D. (2005) Invasive exotic plants suffer less herbivory than non-invasive exotic plants. Biol Lett 1:435-438

Chun YJ, van Kleunen M, Dawson W (2010) The role of enemy release, tolerance and resistance in plant invasions: linking damage to performance. Ecol Lett 13:937-946

Colautti RI, Ricciardi A, Grigorovich IA, MacIsaac HJ (2004) Is invasion success explained by the enemy release hypothesis? Ecol Lett 7:721-733

Crawley MJ (1989) Insect herbivores and plant population dynamics. Annu Rev Ecol Syst 34:531564

Crawley MJ (2007) The R book. John Wiley, New York

Daehler CC (2001) Darwin's naturalization hypothesis revisited. Am Nat 158:324-330

Darwin C (1859) On the origin of species by means of natural selection. Murray, London 
Dawson W, Burslem D, Hulme PE (2009) Herbivory is related to taxonomic isolation, but not to invasiveness of tropical alien plants. Divers Distrib 15:141-147

Desdevises Y, Legendre P, Azouzi L, Morand S (2003) Quantifying phylogenetically structured environmental variation. Evolution 57:2647-2652

Diez JM, Sullivan JJ, Hulme PE, Edwards G, Duncan RP (2008) Darwin's naturalization conundrum: dissecting taxonomic patterns of species invasions. Ecol Lett 11:674-681

Diniz-Filho JAF, de Sant'Ana CER (1998) An eigenvector method for estimating phylogenetic inertia. Evolution 52:1247-1262

Duncan RP, Williams PA (2002) Darwin's naturalization hypothesis challenged. Nature 417:608609

Felsenstein J (1985) Phylogenies and the comparative method Am Nat 125:1-15

Fenner M, Lee WG (2001) Lack of pre-dispersal seed predators in introduced Asteraceae in New Zealand. New Zeal J Ecol 25:95-99

Fenner M, Cresswell JE, Hurley RA (2002) Relationship between capitulum size and pre-dispersal seed predation by insect larvae in common Asteraceae. Oecologia 130:72-77

Frenzel M Brandl R (2001) Hosts as habitats: faunal similarity of phytophagous insects between host plants. Ecol Entomol 26:594-601

Funk VA, Bayer RJ, Kelley S, Chan R, Watson L, Gemeinholzer B, Schilling E, Panero JL, Baldwin BG, Garcia-Jacas N, Susanna A, Jansen RK (2005) Everywhere but Antarctica: using a supertree to understand the diversity and distribution of the Compositae. Biol Skrif 55:343374

Gaskin, JF, Wilson LM (2007) Phylogenetic relationships among native and naturalized Hieracium (Asteraceae) in Canada and the United States based on plastid DNA sequences. Syst Bot 32:478-485 
Gilbert GS, Webb CO (2007) Phylogenetic signal in plant pathogen-host range. P Natl Acad Sci USA 104:4979-4983

Gross RS, Werner PA, Hawthorn WR (1980) The biology of Canadian weeds 38: Arctium minus (Hill) Bernh. and A. lappa L. Can J Plant Sci 60:621-634

Hawkes CV (2007) Are invaders moving targets? The generality and persistence of advantages in size, reproduction, and enemy release in invasive plant species with time since introduction. Am Nat 170:832-843

Hawthorn WD, Hayne PD (1978) Seed production and pre-dispersal seed predation in the biennial composite species, Arctium minus (Hill) Bernh. and A. lappa L. Oecologia 34:283-295

Hill SB, Kotanen PM (2009) Evidence that phylogenetically novel non-indigenous plants experience less herbivory. Oecologia 161:581-590

Hill SB, Kotanen PM (2010) Phylogenetically structured damage on Asteraceae: susceptibility of native and exotic species to foliar herbivores. Biol Invasions 12:3333-3342

Holt RD (1977) Predation, apparent competition, and structure of prey communities. Theor Popul

Joshi J, Vrieling K (2005) The enemy release and EICA hypothesis revisited: incorporating the fundamental difference between specialist and generalist herbivores. Ecol Lett 8:704-714

Keane RM, Crawley MJ (2002) Exotic plant invasions and the enemy release hypothesis. Trends Ecol Evol 17:164-170

Kim KJ, Choi KS, Jansen RK (2005) Two chloroplast DNA inversions originated simultaneously during the early evolution of the sunflower family (Asteraceae). Mol Biol Evol 22:1783-1792

Levine JM, Adler PB, Yelenik SG (2004) A meta-analysis of biotic resistance to exotic plant invasions. Ecol Lett 7:975-989 
405 Lewinsohn TM, Novotny V, Basset Y (2005) Insects on plants: diversity of herbivore assemblages

406 revisited. Annu Rev Ecol Syst 36:597-620

407 Liu H, Stiling P (2006) Testing the enemy release hypothesis: a review and meta-analysis. Biol

$408 \quad$ Invasions 8:1535-1545

409 Liu H, Stiling P, Pemberton RW (2007) Does enemy release matter for invasive plants? evidence

410 from a comparison of insect herbivore damage among invasive, non-invasive and native

$411 \quad$ congeners. Biol Invasions 9:773-781

412 Louda, SM (1983) Seed predation and seedling mortality in the recruitment of a shrub,

413 Haplopappus venetus (Asteraceae), along a climatic gradient. Ecology 64:511-521

414 Louda SM, Kendall D, Connor J, Simberloff D (1997) Ecological effects of an insect introduced

415 for the biological control of weeds. Science 277:1088-1090

416 Louda SM, O'Brien CW (2002) Unexpected ecological effects of distributing the exotic weevil,

417 Larinus planus (F.), for the biological control of Canada thistle. Conserv Biol 16:717-727

418 Louda SM, Pemberton RW, Johnson MT, Follett PA (2003) Nontarget effects - the Achilles’ heel

419 of biological control? Retrospective analyses to reduce risk associated with biocontrol

$420 \quad$ introductions Annu Rev Entomol 48:365-396

421 Louda SM, Potvin MA (1995) Effect of inflorescence-feeding insects in the demography and

422 lifetime fitness of a native plant. Ecology 76:229-245

423 Mack RN (1996) Predicting the identity and fate of plant invaders: Emergent and emerging

$424 \quad$ approaches. Biol Conserv 78:107-121

425 Maron JL, Vilà M (2001) When do herbivores affect plant invasion? Evidence for the natural

426 enemies and biotic resistance hypotheses. Oikos 95:361-373

427 Mason PG Huber JT (2002) Biological control programmes in Canada 1981-2000. CABI

$428 \quad$ Publishing, Ottawa 
429 Mitchell CE, Agrawal AA, Bever JD, Gilbert GS, Hufbauer RA, Klironomos JN, Maron JL,

430 Morris WF, Parker IM, Power AG, Seabloom EW, Torchin ME, and Vazquez DP (2006)

$431 \quad$ Biotic interactions and plant invasions. Ecol Lett 9:726-740

432 Moore RJ (1975) The biology of Canadian weeds, 13. Cirsium arvense (L.) Scop. Can J Plant Sci

$433 \quad 55: 1033-1048$

434 Morton JK, Venn JM (1990) A checklist of the flora of Ontario: vascular plants. University of

435 Waterloo Biology Series, Number 34.,Waterloo

436 Noyes RD (2000) Biogeographical and evolutionary insights on Erigeron and allies (Asteraceae)

437 from ITS sequence data. Plant Syst Evol 220:93-114

438 Odegaard F, Diserud OH, Ostbye K (2005) The importance of plant relatedness for host utilization 439 among phytophagous insects. Ecol Lett 8:612-617

440 Oksanen J, Kindt R, Legendre P, O’Hara B, Simpson GL, Solymos P, Stevens MHH, Wagner H 441 (2009) vegan: Community Ecology Package. R package version 1.15-4. http://CRAN.R442 project.org/package=vegan

443 Parker IM, Gilbert GS (2007) When there is no escape: The effects of natural enemies on native, 444 invasive, and noninvasive plants. Ecology 88:1210-1224

445 Parker JD, Hay ME (2005) Biotic resistance to plant invasions? Native herbivores prefer non$446 \quad$ native plants. Ecol Lett 8:959-967

447 Pearse IS, Hipp AL (2009) Phylogenetic and trait similarity to a native species predict herbivory 448 on non-native oaks. Proc Nat Acad Sci US 106:18097-18102

449 R Development Core Team (2006) R: A language and environment for statistical computing. R $450 \quad$ Foundation for Statistical Computing, Vienna, Austria. URL http://www.R-project.org 451 SAS (2002) JMP. SAS Institute, Cary 
452 Semple JC, Cook RE (2006) Solidago. In: FNAE Committee (eds) Flora of North America.

453 Oxford University Press, Oxford, pp.107-166

454 Strauss SY, Webb CO, Salamin N (2006) Exotic taxa less related to native species are more 455 invasive. P Natl Acad Sci USA 103:5841-5845

456 Strong DR, Lawton JH, Southwood R (1984) Insects on plants. Harvard University Press,

$457 \quad$ Cambridge

458 Thuiller W, Gallien L, Boulangeat I, de Bello F, Münkemüller T, Roquet C, Lavergne S (2010)

459 Resolving Darwin’s naturalization conundrum: a quest for evidence. Diversity Distrib

$460 \quad 16: 461-475$

461 Torchin ME, Mitchell CE (2004) Parasites, pathogens, and invasions by plants and animals. Front $462 \quad$ Ecol Environ 2:183-190

463 Webb CO, Ackerly DD, McPeek MA, Donoghue MJ (2002) Phylogenies and community ecology.

$464 \quad$ Annu Rev Ecol Syst 33: 475-505

465 Webb CO, Donoghue MJ (2005) Phylomatic: tree assembly for applied phylogenetics. Mol Ecol

$466 \quad$ Notes 5:181-183

467 Weiblen GD, Webb CO, Novotny V, Basset Y, Miller SE (2006) Phylogenetic dispersion of host

$468 \quad$ use in a tropical insect herbivore community. Ecology 87:S62-S75

469 Whitton J, Wallace RS, Jansen RK (1995) Phylogenetic-relationships and patterns of character

470 change in the tribe Lactuceae (Asteraceae) based on chloroplast DNA restriction site

$471 \quad$ variation. Can J Botany 73:1058-1073

472 Zuefle ME, Brown WP, Tallamy DW (2008) Effects of non-native plants on the native insect

473 community of Delaware. Biol Invasions (2008) 10:1159-1169

474 Zwölfer H (1998) Evolutionary and ecological relationships of the insect fauna of thistles. Annu

$475 \quad$ Rev Entomol 33:103-122 
476 Table 1 ANCOVA model for 35 Asteraceae describing the relationship between the Z-

477 transformed proportion of their capitula damaged by seed predators and their origin (exotic or

478 native) plus the five significant phylogenetic eigenvectors identified using Principal Co-ordinate

479 Analysis. The overall variance explained by the eigenvectors was $r^{2}{ }_{\text {adj }}=0.63$, versus $r^{2}$ adj $=0.03$

480 for species' origins. Numbers in square brackets represent the rank of each eigenvector among the

48134 used as potential phylogenetic predictors; lower numbers represent eigenvectors that have

482 longer periods and explain broader patterns of phylogenetically structured variation (see Fig. 1).

\begin{tabular}{lllll}
\hline Term & Estimate & $\mathrm{SE}$ & $\mathrm{t}_{28}$ & $\mathrm{p}$ \\
\hline Intercept & -1.565 & 0.182 & -8.576 & $<0.001$ \\
Origin & -1.119 & 0.239 & 1.865 & $0.073^{*}$ \\
Eigenvector[2] & 0.020 & 0.006 & 3.323 & 0.002 \\
Eigenvector[3] & -0.030 & 0.008 & -3.656 & 0.001 \\
Eigenvector[8] & 0.062 & 0.017 & 3.599 & 0.001 \\
Eigenvector[19] & -0.090 & 0.030 & -3.000 & 0.006 \\
Eigenvector[20] & 0.118 & 0.032 & 3.638 & 0.001 \\
\hline \hline
\end{tabular}




\section{Figure Legends}

486 Fig. 1 Plot of the community phylogeny of the 35 species of Asteraceae that were used in this

487 study; exotics are indicated in bold. The first column of scores represents the untransformed mean 488 proportion of capitula damaged by seed predators ( \pm SE). The remaining columns are the 489 eigenvector loadings for the five significant eigenvectors used to explain the phylogenetic 490 component of capitular damage (Table 1). Numbers next to lineages indicate where phylogenetic 491 structure in damage was detected by the eigenvectors as referred to in the text. Nomenclature 492 follows Morton and Venn (1990); 1-5 sites were sampled per species (mean = 2.4)

493 Fig. 2 Plots of the Z-transformed proportion of capitula damaged for 35 species of Asteraceae, 494 regressed against the five significant eigenvectors identified using forward selection multiple 495 regression. Significance for each slope is as follows: a) eigenvector 2, b) eigenvector 3, c) 496 eigenvector 8, d) eigenvector 19, and e) eigenvector 20. Triangles represent mean damage for 497 native species, and circles for exotic species. Test statistics, degrees of freedom, and p-values are 498 presented for slopes

499 Fig. 3 Plots of the Z-transformed proportion of capitula damaged for 14 exotic species of 500 Asteraceae, versus phylogenetic distance (in millions of years) to other Asteraceae at KSR. All 501 relationships were non-significant: a) distance to all Asteraceae, b) distance to closest Asteraceae, 502 c) mean distance to all native Asteraceae, and d) mean distance to closest native Asteraceae 
Figure1

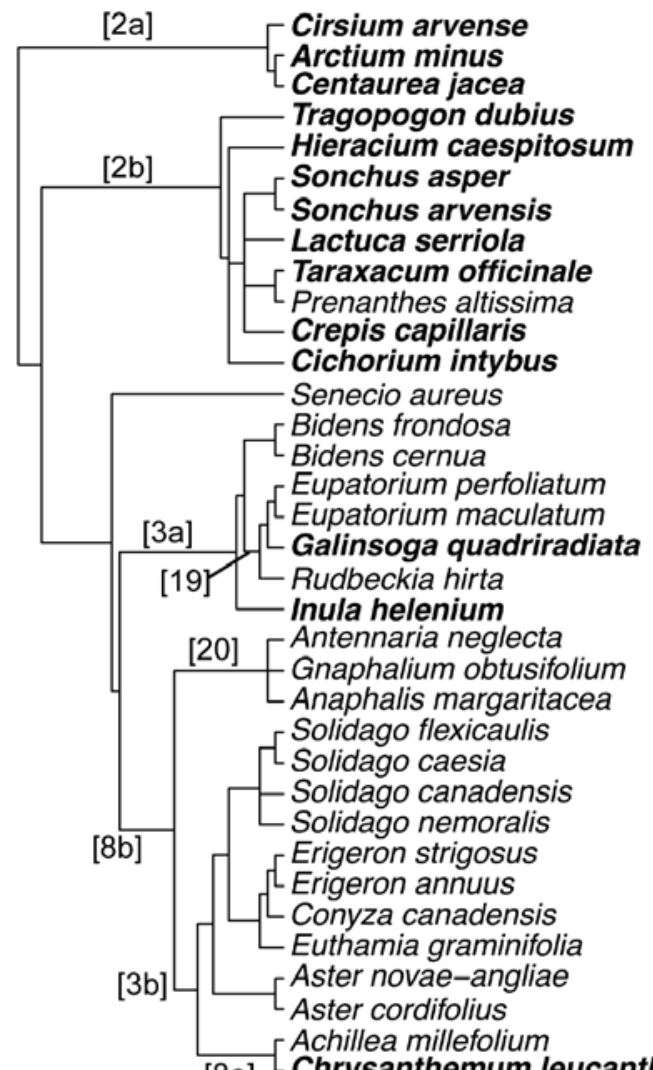

[8] Chrysanthemum leucanthemum

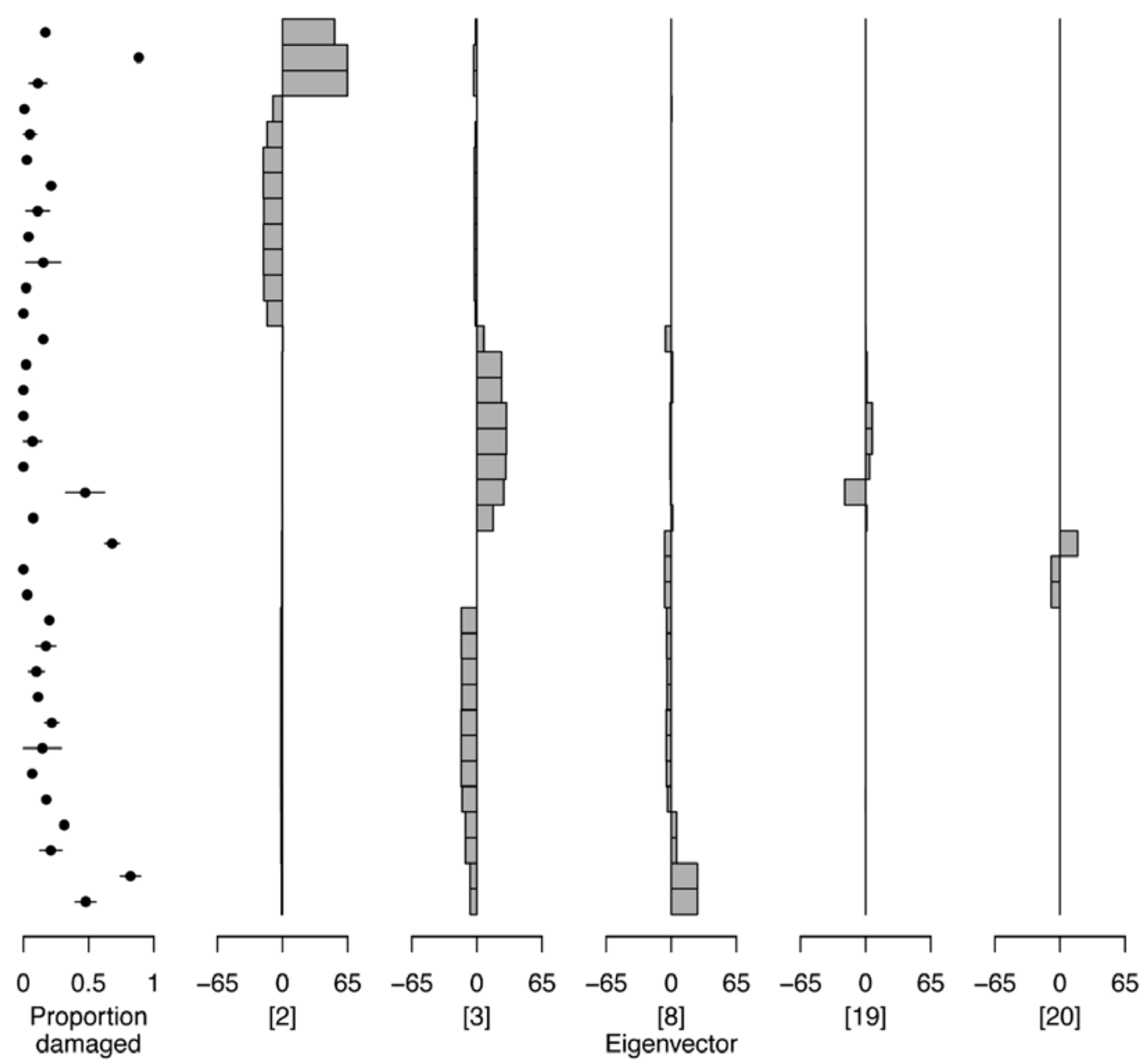


Figure 2
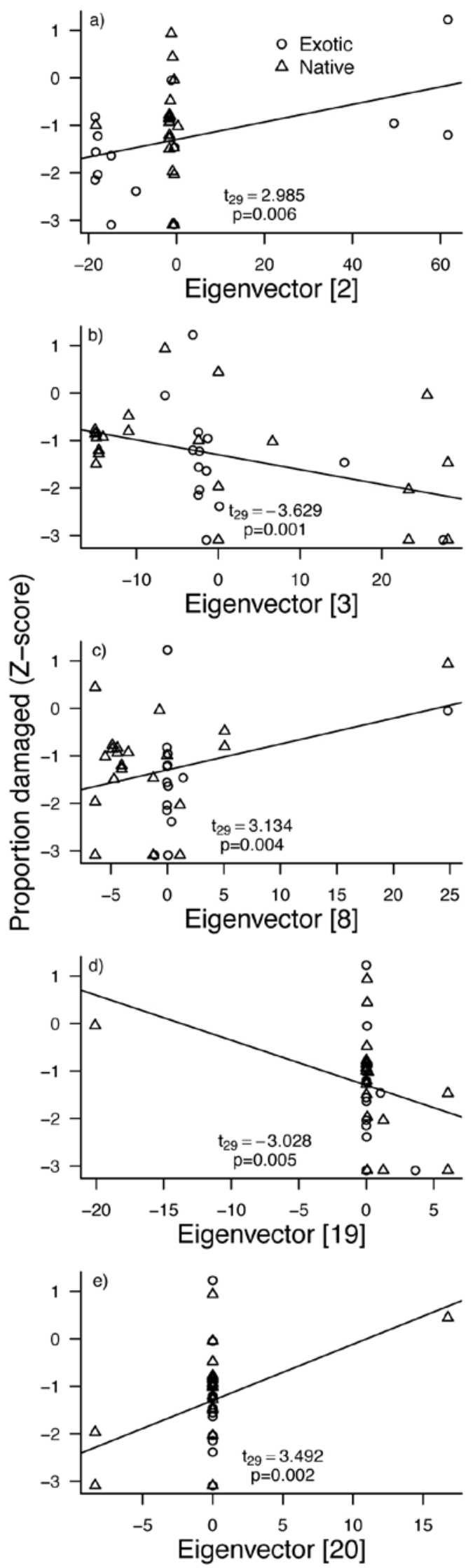
Figure 3

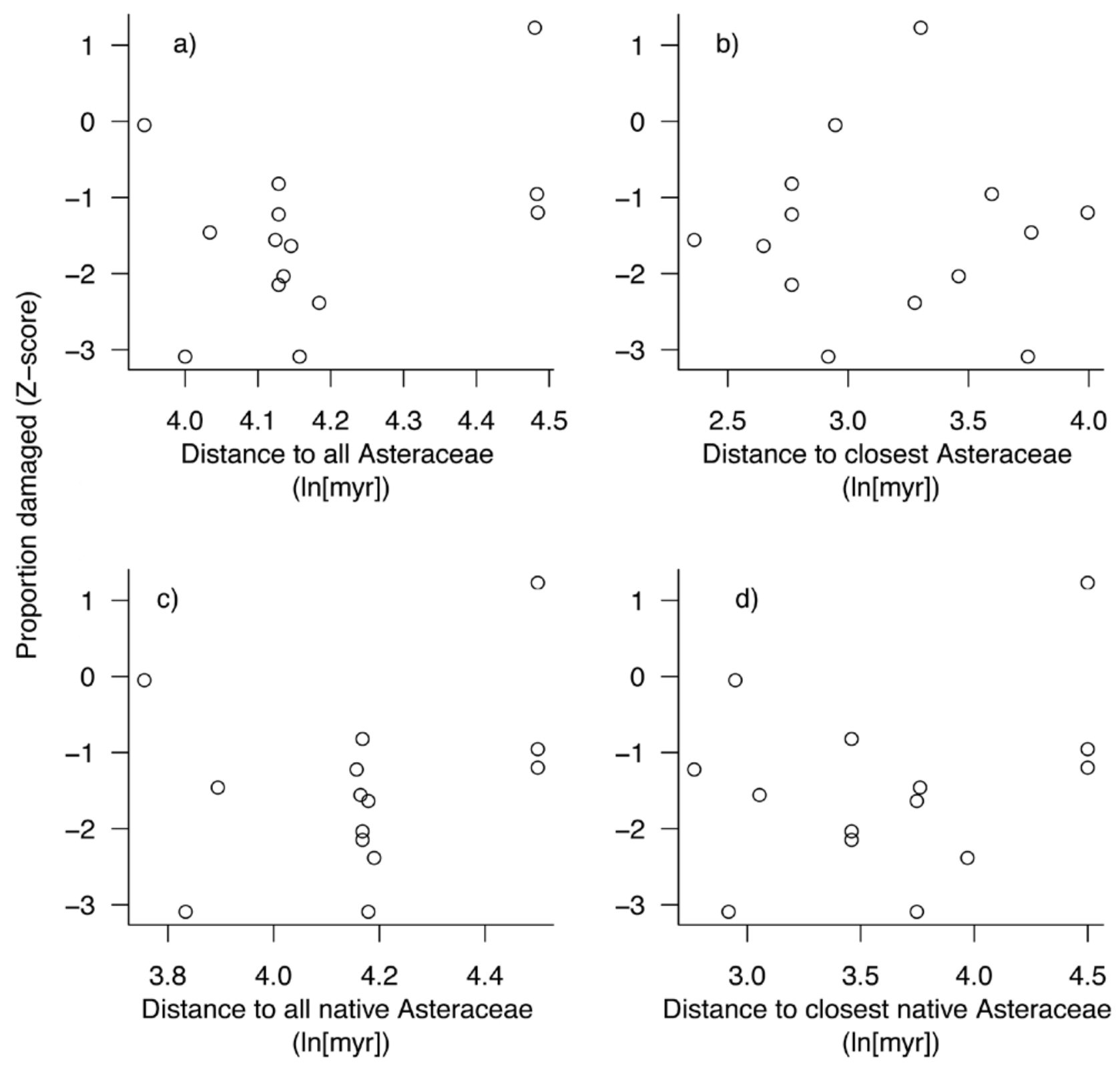

